\title{
O LUGAR QUe O Estado ENCONTRA A POPUlaÇÃo: PERCEPÇÃo do DOCENTE NO SERVIÇO PÚBLICO
}

THE PLACE IN WHICH THE STATE MEETS THE POPULATIONS: PERCEPTION OF THE TEACHER IN THE PUBLIC SERVICE

EL LUGAR DONDE EL ESTADO SE ENCUENTRA CON LA POBLACIÓN: LA PERCEPCIÓN DEL DOCENTE EN EL SERVICIO PÚBLICO

\author{
José Vinicius da Costa \\ Filho

\section{iD 9} \\ Doutorado em Ciência Política \\ (UFPE) \\ Professor no Instituto Federal de \\ Mato Grosso (IFMT) \\ Professor do Mestrado Profissional \\ em Educação Profissional e \\ Tecnológica (ProfEPT/IFMT) \\ jose.costafilho@cba.ifmt.edu.br
}

\section{Tatiane de Oliveira

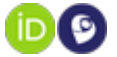

Doutoranda no Programa de PósGraduação em Estudos de Linguagens (UFMT)

Professora no Instituto Federal de Mato Grosso (IFMT)

tatioliveirasp@hotmail.com

\section{Luiz Renato de Souza \\ Pinto \\ (iD) 9}

Doutorado em Literaturas de Língua Portuguesa (UNESP)

Professor no Instituto Federal de

Mato Grosso (IFMT)

Professor do Mestrado Profissional

em Educação Profissional e

Tecnológica (ProfEPT/IFMT)

luiz.pinto@cba.ifmt.edu.br

\section{Milena Raquel Vital dos \\ Santos}

Bacharel em Secretariado Executivo milena18raquel@gmail.com

\begin{abstract}
Resumo
Analisa-se a percepção dos docentes do curso bacharelado em Secretariado Executivo do IFMT - Campus Cuiabá Octayde Jorge da Silva em relação à sua atuação na política pública educacional, a partir de conceitos de burocracia de nível de rua. O estudo exploratório é qualitativo e faz uso de entrevista semiestruturada. Os resultados são: 1) o docente está inserido em uma estrutura burocrática institucional que pauta a sua atuação e discricionariedade; 2) foram identificadas expectativas diversas, propriamente discentes desmotivados, instituição incapaz de articular um esforço pedagógico convergente, docentes que enfrentam um ambiente não ideal sem incentivos institucionais para práticas pedagógicas comuns; 3) a discricionariedade do docente se relaciona com as condições do discente; 4) o docente possui liberdade e não sofre ameaças da gestão superior; 5) dissintonia entre o que deseja o discente, planeja a gestão e executa o docente. Este artigo contribui com a agenda que trata do trabalho docente na rede pública de educação.

Palavras-chave: Educação. Burocracia de nível de rua. Prática docente. Secretariado Executivo.
\end{abstract}

Recebido em: 14 de outubro de 2021.

Aprovado em: 21 de dezembro de 2021.

Como citar esse artigo (ABNT):

COSTA FILHO, José Vinicius da et al. O lugar que o Estado encontra a população: percepção do docente no serviço público.

Revista Prática Docente, v. 7, n. 1, e002, 2022.

http://doi.org/10.23926/RPD.2022.v7.n1.e002.id1324 


\begin{abstract}
The perception of street-level bureaucrats, specifically professors of the Bachelor of Executive Secretariat at IFMT - Campus Cuiabá Octayde Jorge da Silva in relation to their role in educational public policy is analyzed. The exploratory research is qualitative and uses semi-structured interviews. The results are: 1) the professor is inserted in an institutional bureaucratic structure that guides his performance and discretion; 2) diverse expectations were identified, specifically unmotivated students, an institution incapable of articulating a convergent pedagogical effort, professors who face a non-ideal environment without institutional incentives for common pedagogical practices; 3 ) the professor's discretion is related to the student's conditions; 4) the professors has freedom and is not threatened by higher management; 5) mismatch between what the student wants, plans the management and executes the professors. This study contributes to the agenda that deals with teaching work in the public education network.
\end{abstract}

Keywords: Education, Street-level bureaucracy, Teacher's practice, Executive Secretariat.

\title{
Resumen
}

Se analiza la percepción de los burócratas de la calle, específicamente profesores de la Licenciatura de la Secretaría Ejecutiva de la IFMT - Campus Cuiabá Octayde Jorge da Silva, en relación a su rol en la política pública educativa. La investigación exploratoria es cualitativa y utiliza entrevistas semiestructuradas. Los resultados son: 1) el profesor se inserta en una estructura burocrática institucional que orienta su desempeño y discreción; 2) se identificaron diversas expectativas, específicamente estudiantes desmotivados, una institución incapaz de articular un esfuerzo pedagógico convergente, docentes que enfrentan un entorno no ideal sin incentivos institucionales para prácticas pedagógicas comunes; 3) la discreción del maestro está relacionada con las condiciones del estudiante; 4) el maestro tiene libertad y no se ve amenazado por la alta dirección; 5) desajuste entre lo que quiere el alumno, planifica la gestión y lo ejecuta el docente. Este estudio contribuye a la agenda que aborda la labor docente en el sistema de educación pública.

Palabras clave: Educación. Burocracia al nivel de la calle. Práctica docente. Secretario Ejecutivo. 


\section{INTRODUÇÃO}

No Brasil, a educação é tratada como um direito social e a Constituição Federal de 1988 $(\mathrm{CF} / 88)$ desenha a macro política pública da educação reservando uma seção inteira para falar desse tema. A conotação desse meio ambiente dinâmico da educação guarda relação com a teoria de Lipsky $(1969 ; 1980)$, especialmente quando o pesquisador aponta para uma alta discricionariedade e autonomia na ponta da execução do serviço público, em que se pesem as limitações institucionais da macro política pública educacional. O "lugar" onde o serviço do governo encontra o cidadão (LIPSKY, 1969) ainda é pouco explorado pela agenda de pesquisa, tanto da educação quanto da política pública.

A pesquisa tem por objetivo analisar a percepção dos docentes do curso de bacharelado em Secretariado Executivo (SE), do Instituto Federal de Mato Grosso (IFMT), Campus Cuiabá Octayde Jorge da Silva, concernente à sua atuação na política pública de educação enquanto burocratas de nível de rua ${ }^{1}$. O curso serve como pano de fundo para revelar como a política pública de educação é implementada pelo docente, considerando o momento de interação entre 'cliente' (discentes) e funcionários do governo (docentes).

A pesquisa é exploratória e qualitativa, com uso da ferramenta de entrevistas semiestruturadas com docentes do curso de SE. A justificativa do estudo está pautada na contribuição autêntica da literatura que estuda, em primeiro lugar, a intersecção entre "educação e burocracia" no seu viés mais prático (COSTA FILHO, GONÇALVES-COSTA, COSTA; 2018; COSTA FILHO, COSTA, GONÇALVES-COSTA, 2017; SILVA, 2016). O segundo aspecto é empírico e considera tanto o fato do IFMT, campus Cuiabá Octayde Jorge da Silva, ser a maior e mais antiga instituição da rede, em Mato Grosso, quanto o curso de SE possuir em sua trajetória algumas avaliações positivas. Por exemplo, no Exame Nacional de Desempenho de Estudantes (ENADE) de 2012 recebeu nota 5 e, no ano de 2017, obteve a avaliação "Muito Boa" no Guia de Estudante da Editora Abril. Nesse ínterim, revela-se como um objeto importante de estudo para analisar as pressões, as relações e as decisões que envolvem o trabalho do docente. O terceiro é metodológico e complementa o segundo, visto que a ferramenta qualitativa se mostra vocacionada para demonstrar com maior potencial de profundidade o momento em que a burocracia encontra o cidadão.

\footnotetext{
${ }^{1}$ De acordo com Lipsky (1969), denomina o servidor público que interage diretamente com o cidadão/cliente na política pública estatal.
} 
O artigo está dividido em seções. Na primeira encontra-se a introdução. A segunda se perfaz na sustentação teórica que dialoga com as teorias da educação e da política pública. A terceira apresenta o curso de bacharelado em SE. A quarta expõe a metodologia da pesquisa, os resultados e sua discussão. A quinta seção apresenta as considerações finais, onde estão pontuadas as noções mais relevantes observadas.

\section{BUROCRACIA DE NÍVEL DE RUA E A EDUCAÇÃo}

O termo "burocratas de nível de rua" pode ser entendido como "trabalhadores de serviço público que interagem diretamente com os cidadãos no curso de seus empregos e que têm discernimento substancial na execução de seu trabalho" ${ }^{2 \prime}$ (LIPSKY, 1980, p. 3). A teoria foca na interação entre os cidadãos e os funcionários públicos e, a partir disso, desenvolve uma explicação parcimoniosa do comportamento organizacional governamental dessa interação, fazendo mais compreensíveis certos problemas desse momento da política pública em que o governo encontra o cidadão. (LIPSKY, 1969; 1980).

Costa Filho, Gonçalves-Costa e Costa (2018) propõem o transbordamento da teoria da burocracia de nível de rua, comumente utilizado pela área das políticas públicas, para estudos na área da educação. Alinhados a essa provocação, a presente pesquisa aproxima a perspectiva teórica de interesse com debates próprios da educação, almejando basilar a explicação do objetivo proposto, qual seja, descrever a percepção dos docentes do curso de bacharelado em $\mathrm{SE}$, em relação à sua atividade docente, a partir da teoria citada.

No Brasil, a CF/88 reservou um espaço de proeminência para o tema educação na medida em que esse direito social é tratado de forma detalhada em relação ao desenho da política pública pretendida pelo Estado brasileiro. Todo o esforço estatal culmina na busca pela oferta da educação a toda sociedade do país.

A educação perpassa a vida e a sociedade traz consigo muitos movimentos como oportunidades, alegrias, conquistas, vitórias, reflexões etc., bem como as tristezas, as derrotas, as dificuldades, os conflitos, as diversidades, "ela já tem uma história. Ela se inspira na dialética" (GADOTTI, 2004, p. 28). Tais movimentos transformam tanto o discente quanto o docente: "a práxis é ativa, é vida, dá movimento à realidade, transforma-a e é por ela transformada" (FRANCO, 2008b, p. 82).

\footnotetext{
2 No original: "Public service workers who interact directly with citizens in the course of their jobs, and who have substantial discretion in the execution of their work are called street-level bureaucrats in this study" (Tradução nossa).
} 
O presente artigo se interessa em analisar a relação instituída no âmbito da educação pública. Na ponta do serviço público, os docentes mediam o processo de ensino-aprendizagem junto aos discentes. O momento controvertido em que o governo encontra o cidadão, ou seja, a interseção entre burocracia (a prática docente) e o cidadão é marcada por relações diversas que interferem na implementação da política pública de educação.

$\mathrm{Na}$ área da Educação, a abordagem analítica de conceituar o docente como burocrata de nível de rua ainda está amadurecendo. Apesar disso, pesquisas recentes vêm dando impulso a mencionada perspectiva teórica.

Puentes-Montoya (2018) analisa os burocratas de nível de rua da política educacional do Estado de São Paulo, buscando dar insumos para a proposição de arranjos institucionais simples com foco no aprendizado dos alunos, sem sacrificar o bem-estar dos professores. A discricionaridade do docente, em sua face de autonomia, é destacada para debater as suas condições de trabalho e de saúde. Os resultados apontam iniciativas realizadas no Estado que garantem a autonomia dos professores e fortalecem a profissão, visando o cuidado paralelo do indivíduo e do educador para possibilitar a correta implementação da política pública.

Barreto, Costa e Mediotte (2020) estudam as formações discursivas relativas à abordagem acadêmica sobre a discricionariedade dos burocratas de nível de rua a partir da implementação de políticas públicas diversas, dente elas a Educação. A pesquisa realiza uma revisão sistemática nessa literatura e, com auxílio da análise de conteúdo, categoriza a amostra de vinte e um trabalhos pelo tipo de discricionaridade aplicado nas investigações. O resultado revela a academia brasileira tratando a discricionariedade em consonância com a teoria. No entanto, revela que a discussão nessa perspectiva teórica é recente.

Exner, Corrêa, Lotta e Farah (2021) utilizam a abordagem de burocracia de nível de rua para explorar os obstáculos postos a professoras em implementar as orientações de documentos normativos brasileiros que defendem a incorporação da perspectiva de gênero na educação. A pesquisa intersecciona as normas que norteiam a política educacional brasileira, que incluem a dimensão de gênero, com a literatura que trata de gênero, psicologia e educação. Os resultados apontam que as diretrizes analisadas são ambíguas - frutos de disputas políticas -, e pouco acessíveis para as professoras, as quais, imersas em um contexto histórico e socialmente pautado por desigualdades de gênero, tendem a reproduzir padrões e comportamentos dissonantes daqueles estabelecidos normativamente. 
Costa Filho, Gonçalves-Costa e Costa (2018) expõem que, desde os primeiros trabalhos que constituíram a teoria de Lipsky, o docente é utilizado como exemplo de burocrata de nível de rua, na medida em que a sua relação com o cidadão (discente) ocorre no 'lugar' problemático da interação entre clientes e funcionários do governo. O recorte em pauta privilegia a implementação da política pública com foco na ampla gama de variáveis que envolvem o momento em que o serviço público encontra o cidadão.

Lotta (2010, p. 36) aponta que existem duas razões centrais para os burocratas de nível de rua ganharem proeminência na agenda de pesquisa: 1) a primeira é que toda análise sobre o escopo e o foco dos serviços públicos diz respeito diretamente ao debate acerca da atividade e a função exercida por esses trabalhadores; 2) a segunda razão é que os agentes de rua têm grande impacto na vida das pessoas, na medida em que socializam espaço na comunidade e expectativas sobre os serviços públicos; determinam a elegibilidade dos cidadãos para acessarem os benefícios ou receberem sanções; dominam a forma de tratamento dos cidadãos e mediam aspectos da relação institucional dos cidadãos com o Estado.

Na ponta do serviço público da educação, o saber docente advém de múltiplos saberes, entre eles as suas formações e experiências de vida e profissionais, além do que é aprendido no cotidiano das práticas pedagógicas, no sentido de práxis (TARDIF, 2002), que varia conforme o tempo e o contexto. Os saberes acumulados do docente encontram, na intersecção entre a burocracia e o cliente, um cenário complexo marcado pela percepção quanto ao serviço prestado (pelos burocratas), de um lado, e recebido (pelos clientes) de outro, o qual, por sua vez, é interpenetrado por pressões, dilemas, definições e ressignificações oriundos dos limites (regras) e das discricionariedades existentes (autonomia de atuação), resultando em políticas públicas próprias a cada realidade (COSTA FILHO; GONÇALVES-COSTA; COSTA, 2018).

Nessa perspectiva, as determinações constantes da estrutura institucional e das regras do jogo têm no projeto político-pedagógico do curso um dispositivo que demarca os limites e os constrangimentos da política pública de educação. No viés político, segundo Veiga (2003, p. 272), “o projeto político-pedagógico [...] está voltado para a burocratização da instituição educativa, transformando-a (a prática pedagógica) em mera cumpridora de normas técnicas e de mecanismos de regulação convergentes e dominadores".

Estabelecendo uma relação dialética com essa burocratização, para Certeau (1994), as práticas pedagógicas geralmente não são frutos "apenas" dessas imposições, e sim, muitas vezes, alinhadas com Hooks (2017), são "transgressoras", no sentido de resistirem ao sistema, 
às imposições técnicas, coloniais e até do próprio governo. Quanto à aprendizagem dos discentes, é importante demarcar que esses também têm as suas diferentes culturas, costumes, raças, identidades, objetivos, experiências, condições sociais, econômicas, entre outros. Assim, Candau (2008, p. 15) aponta que é preciso fazer da sala de aula "um espaço de cruzamento de culturas, fluido e complexo, atravessado por tensões e conflitos". Freire (2004) arrebata ao ensinar que a autonomia do professor reside na harmonia entre prática e teoria, entre ensino e aprendizado. Logo, a discricionaridade docente revelada nessa autonomia é marcada por constituir uma construção histórica em constante transformação, fiadora do processo pedagógico entre educando e educado.

Percebe-se, nessa dinâmica entre os limites institucionais (política pública) e a prática do docente, a emersão dos problemas de interesse da teoria da burocracia de nível de rua de Lipsky $(1969 ; 1980)$. Três premissas básicas definem o trabalho desses funcionários do Estado que figuram na ponta do serviço público:

1. O burocrata em questão é chamado a interagir constantemente com os cidadãos no curso regular de seu trabalho. 2. Embora trabalhe dentro de uma estrutura de burocracia, sua independência no trabalho é bastante extensa. Um componente dessa independência é a discricionariedade na tomada de decisões; mas a independência no desempenho do trabalho não é limitada a essa característica. A atitude e a abordagem geral de um burocrata de nível de rua em relação ao seu cliente podem afetar significativamente o cliente. Essas considerações são mais amplas do que o inicialmente se imagina. 3. O impacto potencial de suas decisões sobre os cidadãos com quem ele trata é bastante extenso ${ }^{3}$ (LIPSKY, 1969, p. 2).

O docente, nesse cenário, é retratado como um ator que lida com condições muitas vezes marcadas por: 1) recursos inadequados - desenvolvem seu trabalho em salas superlotadas, com materiais inadequados e clientes que necessitam de atenção pessoal intensa; 2) ameaças e desafios à autoridade - por vezes o docente trabalha em meio a uma situação latente de ameaças de danos físicos e psicológicos; 3 ) expectativas sobre o desempenho do trabalho - os burocratas de níveis de rua, em geral, desempenham seus trabalhos em resposta a expectativas ambíguas e contraditórias, não sendo estes livres para determinar sua clientela (LIPSKY, 1969).

Desse modo, a teoria da burocracia de nível de rua está aproximada da área da educação, do ensino e da prática docente, tendo em vista que é relevante para a agenda de pesquisa

3 No original: "1. He is called upon to interact constantly with citizens in the regular course of his job. 2. Although he works within a bureaucratie structure, his independence on the job is fairly extensive. One component of this independence is discretion in making decisions; but independence in job performance is not limited to discretion. The attitude and general approach of a street-level Bureaucrat toward his client may affect his client significantly. These considerations are broader than the term discretion suggests" (Tradução nossa). 
entender o docente para além de um mero implementador de políticas públicas de educação, pois são sujeitos imersos num ambiente complexo que possui discricionariedade para a sua ação, para (re)formular os programas, projetos e planejamento delimitados pela burocracia superior, tornando seu comportamento, o comportamento da instituição na qual representa (LOTTA, 2010). O objetivo proposto nesta pesquisa está situado justamente nos dilemas apontados acima.

\section{O CuRSo de Bacharelado em Secretariado Executivo do IFMT - CaMpus Cuiabá OCTAyde JoRge da Silva}

Os Institutos Federais são unidades de referência em ensino técnico, integrado e superior, instituídas pela Lei n. ${ }^{\circ}$ 11.892/2008 no âmbito do sistema federal de ensino, a Rede Federal de Educação Profissional, Científica e Tecnológica (RFEPCT). Sua constituição ocorreu a partir da reunião dos Centros Federais de Educação Tecnológica (Cefets), das escolas técnicas e agrotécnicas federais e das escolas técnicas vinculadas às universidades federais. $\mathrm{O}$ IFMT faz parte dessa rede de educação profissional e tecnológica e atualmente possui 19 campi (dentre as unidades sedes e avançadas).

O IFMT - Campus Cuiabá Octayde Jorge da Silva é o Campus mais antigo e empresta a sua idade centenária ao Instituto como um todo. A sua trajetória iniciou a partir da Escola de Aprendizes Artífices de Mato Grosso, que foi fundada através do Decreto n. ${ }^{\circ}$ 7.566/1909, de autoria do Presidente da República - Nilo Peçanha (patrono da educação profissional).

Durante os cem anos de existência, a referida unidade passou por cinco mudanças institucionais; a última ocorreu com o advento da Lei n. ${ }^{\circ} 11.892 / 2008$, que cria os Institutos Federais e vincula o então Centros Federais de Educação Tecnológica de Mato Grosso $(\mathrm{CEFET} / \mathrm{MT})^{4}$ como um dos campi dessa nova estrutura que tem em seu vértice uma reitoria central e passa a ser denominado IFMT - Campus Cuiabá Octayde Jorge da Silva.

No ano de 2010, com eixo tecnológico de gestão e negócios, iniciou-se o curso de bacharelado em SE, do IFMT, campus Cuiabá Octayde Jorge da Silva, com duração de 03 anos. O Projeto Pedagógico do Curso (PPC, p. 12) teve a sua $1^{\text {a }}$ reformulação aprovada pela Resolução CONSUP n. ${ }^{\circ}$ 13, de 16 de abril de 2021 e consta como objetivo do curso “proporcionar aos estudantes [...] conhecimentos específicos da área secretarial, além de conhecimentos generalistas que priorizem o trabalho analítico, criativo, reflexivo,

4 Antiga denominação da unidade do Campus Cuiabá Octayde Jorge da Silva. 
empreendedor e tecnológico, atendendo as demandas da sociedade", com 35 novas vagas, em média, por semestre.

Salienta-se que o citado bacharelado surge pela necessidade do mercado e importância da profissão. A atividade de SE é regulamentada pela Lei n. ${ }^{\circ}$ 7.377, de 30 de setembro de 1985, que dispõe sobre o exercício da profissão de secretário, e prevê outras providências, com alterações amparadas na pela Lei n. ${ }^{0} 9.261$ de 10 de janeiro de 1996, que determinam as atribuições básicas desse profissional. Em geral, essas atribuições estão respaldadas nos quatro pilares da profissão: assessoria, gestão, consultoria e empreendedorismo (PORTELA; SCHUMACHER; BORTH, 2013).

Em pesquisa recente, Oliveira e Portela (2021, p. 31) contextualizam que, no período de sua oferta, “de 2010/1 a 2020/2, 641 estudantes fizeram a matrícula no curso de SE. Destes, 547 (85,34\%) são mulheres e 94 (14,66\%) são homens”. A mesma pesquisa identificou, ainda, 90,24\% de empregabilidade em uma amostra de 41 egressos que responderam um questionário sobre o tema (OLIVEIRA; PORTELA, 2021).

O curso é amparado nas Diretrizes Curriculares Nacionais (DCN), aprovada na Resolução MEC n. ${ }^{\circ}$ 03, de 23 de junho de 2005, e busca a formação do secretário executivo nas competências e habilidades, tais como:

I - capacidade de articulação [...]; II - visão generalista da organização [...]; III exercício de funções gerenciais, com sólido domínio sobre planejamento, organização, controle e direção; IV - utilização do raciocínio lógico, crítico e analítico, [...]; V - habilidade de lidar com modelos inovadores de gestão; VI - domínio dos recursos de expressão e de comunicação [...], inclusive nos processos de negociação e nas comunicações interpessoais ou inter-grupais; VII - receptividade e liderança para o trabalho em equipe [...]; VIII - adoção de meios alternativos relacionados com a melhoria da qualidade e da produtividade dos serviços [...]; IX - gerenciamento de informações, assegurando uniformidade e referencial para diferentes usuários; X gestão e assessoria administrativa [...]; XI - capacidade de maximização e otimização dos recursos tecnológicos; XII - eficaz utilização de técnicas secretariais, com renovadas tecnologias, [...] e fidelidade no fluxo de informações; e XIII - iniciativa, criatividade, [...] abertura às mudanças, consciência das implicações e responsabilidades éticas do seu exercício profissional. (BRASIL, 2005, p. 04).

Desse modo, o secretário executivo deve ser preparado para trabalhar de forma generalista, crítica, inovadora, ética e técnica ${ }^{5}$. Corroborando com a ideia de atuação generalista, Oliveira e Portela (2021, p. 36) acentuam as respostas dos egressos quando questionados sobre os "motivos da escolha do curso" de SE no IFMT - Campus Octayde Jorge

50 trabalho técnico refere-se às técnicas secretariais para atender as diversas áreas organizacionais no âmbito privado ou público. 
da Silva: "pela quantidade de áreas que posso conseguir (atuar)"; "por ser um curso que abrange várias áreas"; e "escolhi o curso pela abordagem da grade curricular".

\section{Metodologia, dados e Resultados: A PERCEPÇÃo doCente do CURSO BACHAREL EM SECRETARIADO EXECUTIVO}

A presente seção apresenta a metodologia proposta para atender ao objetivo da pesquisa, bem como expõe os dados coletados e resultados encontrados. A seção será dividida em duas subseções, conforme segue.

\subsection{METODOLOGIA}

O estudo é exploratório, pois a agenda que trata da formação do SE ainda está amadurecendo e, além disso, faz uso de uma perspectiva teórica não usual para a área de educação. Prodanov e Freitas (2013) indicam que a pesquisa exploratória é caracterizada quando o estudo está em fase preliminar e tem como finalidade proporcionar mais informações sobre o assunto investigado, possibilitando sua definição e seu delineamento. Desse modo, facilita a delimitação do tema e a formulação das hipóteses ou para descobrir um novo tipo de enfoque para o assunto (PRODANOV; FREITAS, 2013).

A metodologia é qualitativa visto que trabalha "com o universo de significados, motivos, aspirações, valores e atitudes, o que corresponde a um espaço mais profundo das relações, dos processos e dos fenômenos que não podem ser reduzidos à operacionalização de variáveis" (MINAYO, 1992, p. 21). Para tanto, utiliza-se da ferramenta de entrevista semiestruturada para coleta dos dados primários, que é uma importante técnica para extrair informações sobre o que as pessoas sabem, o que pensam, como agem, sobre as suas expectativas, medos, sentimentos etc.; o que propicia uma gama de elementos que contribuem para o processo de pesquisa (LAKATOS; MARCONI, 2001).

A sistematização da coleta dos dados qualitativos ocorreu da seguinte maneira: realizaram-se entrevistas semiestruturadas com 03 docentes que atuavam no momento da pesquisa, no curso de SE, do IFMT, Campus Cuiabá, de um universo de 23 possíveis 6.

A seleção da amostra foi não probabilística. Apesar disso, optou-se por escolher 01 docente formado em Secretariado Executivo, responsável por disciplina técnica na área direta do curso; 01 docente formado em Administração, responsável por disciplina técnica de área

6 Número de docentes que compõe o Colegiado do Curso, conforme Portaria no. 148/2019/IFMT - Campus Cuiabá Octayde Jorge da Silva. 
afim; e 01 docente formado em Letras/Espanhol, responsável por disciplina que na Instituição são denominadas da área do Núcleo Comum. A amostra foi composta de 02 mulheres e 01 homem. Os entrevistados não serão identificados, sendo qualificados como: Docente 01; Docente 02; e Docente 03.

Os encontros ocorreram no mês de Julho e Agosto de 2020. Contudo, por advento da crise sanitária do COVID-19, as entrevistas foram aplicadas e gravadas por meio de aplicativo de videochamada. As entrevistas buscam explorar as relações, sentimentos e percepções sobre os fenômenos que ocorrem no 'lugar' em que o serviço público encontra o cidadão, nesse caso na mediação da prática docente. Organizaram-se 08 blocos de questões e cada bloco é composto de 01 a 03 perguntas que tratam de um tema comum.

\subsection{A PRÁTICA DE ENSINO E SEUS DESDOBRAMENTOS}

O primeiro bloco de perguntas trata da apresentação e trajetória profissional dos entrevistados. A Docente 01 iniciou na docência no ano de 2019 como substituta do curso analisado. A entrevistada foi, recentemente, discente da instituição no curso de SE e preocupouse com a verticalização do aprendizado, pois já concluiu especialização em Docência Superior e está cursando mais duas, uma em Formação Pedagógica pelo próprio IFMT e outra em Administração de Pessoas.

A Docente 02 trabalha na docência desde o ano de 2000, em 2006 ingressou como substituta no IFMT, dois anos depois, em 2008, tornou-se docente de carreira na mesma instituição. Seus primeiros passos no IFMT ocorreram no curso de SE. A entrevistada também foi discente da instituição. Além disso, é formada em Letras-Licenciatura espanhol/português, especialista em gestão escolar e mestre em Estudos de Linguagem.

O Docente 03 é graduado e mestre em Administração e especialista em Planejamento e Marketing. Em simetria com as demais entrevistadas, o Docente 03 foi discente do IFMT e relata: "sempre tive uma paixão pelo IFMT [...] sou apaixonado pela educação". A experiência docente do entrevistado inicia muito cedo, já na adolescência se voluntariou para acompanhar algumas disciplinas em uma escola pública. No ano de 2013, assim que se formou, ingressou como docente substituto no IFMT. Não muito tempo depois, em 2014, ingressou para docente de carreira da Instituição. Labora no curso de SE desde o segundo semestre da sua docência.

O segundo bloco indaga acerca dos conhecimentos estruturantes no que se refere à área e ao curso de SE (PPC, público alvo e área de atuação). A Docente 01 afirma: "ao entrar, eu já li (o PPC)" e que não conhece todos os docentes do curso. Por outro lado, tem domínio de qual 
é o público-alvo e os quatro pilares de formação do SE, que foram citados mais acima, ou seja, assessoria, gestão, consultoria e empreendedorismo. A Docente 02 esclarece que não possui capacitação específica para o entendimento profundo do SE; contudo, pontua a sua iniciativa em realizar capacitações diversas para "agregar a língua (...) aos conhecimentos técnicos do curso". O Docente 03 explica que não tem formação específica para trabalhar com o SE; assim resolveu "conversar com outros secretários executivos para tentar entender um pouco melhor sobre o papel e a função" e, dessa forma, alinhar melhor suas aulas às demandas da área, além de manter o diálogo constante com os discentes.

Identifica-se, no segundo bloco de perguntas, como o burocrata de nível de rua (o docente) lida com alguns dos principais elementos que limitam e determinam seu trabalho docente, ou seja, o PPC, o seu público-alvo, a atividade laboral da área e os demais docentes. São, portanto, aspectos que Lipsky (1969) denomina de estrutura burocrática ${ }^{7}$, que, no caso em tela, afetam a atividade docente. Assim, todos os entrevistados tiveram a preocupação em conhecer um ou mais elementos que compõem as regras do jogo e o ambiente de sua atividade laboral, isto é, as definições e ressignificações oriundos dos limites - regras formais e informais - que marcam a percepção quanto ao serviço prestado pelos burocratas (COSTA FILHO; GONÇALVES-COSTA; COSTA, 2018). A docente com formação na área direta do curso analisado foi quem demonstrou um acesso mais diversificado aos elementos indagados. Os outros dois docentes que não são da área técnica direta, além de possuírem a sua disposição às normativas do curso, buscaram por meio de capacitações e consultas a terceiros preencher eventuais lacunas existentes quanto às especificidades do SE.

Este segundo bloco demonstra que a gestão do curso, a chefia do departamento e a direção de ensino do campus Cuiabá precisam de um olhar mais cuidadoso quanto à capacitação dos docentes.

O terceiro bloco abordou as expectativas da sociedade e do IFMT em relação à prática docente do entrevistado. A Docente 01 salienta que a sociedade não compreende a relevância do curso e, logo, "a expectativa deles, em relação ao IFMT, é bem baixa”. Por outro lado, defende que o IFMT tem como missão formar para a vida e para o trabalho (missão oficial do IFMT $^{8}$ ); dessa forma, a expectativa da instituição é colocar o discente no "centro do

\footnotetext{
${ }^{7}$ A estrutura burocrática engloba, ainda, outros fatores e elementos para além dos dispostos no parágrafo.

${ }^{8}$ A missão, visão e valores pode ser lida na íntegra no site da instituição: http://ifmt.edu.br/conteudo/ pagina/ missao-visao-e-valores/. Acesso em: 04 out. 2021.
} 
aprendizado" com processos de ensino-aprendizagem mais práticos que instiguem o discente a pensar mais.

Para a Docente 02, a sociedade tem como expectativa em relação à sua disciplina o de "sair dali falantes, proficientes na língua", contudo, ela aponta que o curso de SE não oferece as condições necessárias para tal resultado, no caso "carga horária eficaz, [...] de um laboratório, [...] de material adequado". Nesse cenário, a Docente 02 entende que desenvolve suas atividades com excelência, considerando as condições disponibilizadas, mas pondera e relata que "as expectativas não sejam (sic) concluídas totalmente".

O Docente 03 defende que "a sociedade não conhece muito bem a função de secretário executivo, existe um estigma e um certo estereótipo que não condiz com o verdadeiro papel e a verdadeira função". Afirma, ainda, que não percebe o IFMT discutindo acerca da expectativa da instituição em relação aos professores; dessa maneira, não fica evidente qual seria esse papel ideal, ou seja, "o professor vai lá, ele lê o plano de curso, ele lê o PPC, plano que forma o curso, mas ele não tem uma discussão com outros profissionais, principalmente com secretários executivos, que ajudem ele".

Nesse terceiro bloco, as expectativas da sociedade e da instituição ${ }^{9}$ são colocadas em evidência. O reconhecimento das expectativas contribui para que o burocrata possa mediar a relação institucional dos cidadãos com o Estado (LOTTA, 2010). Inicialmente, restou pacífica a constatação da divergência existente entre as expectativas da sociedade e da instituição. Os três entrevistados descrevem o desconhecimento da sociedade acerca da finalidade do curso analisado, bem como as expectativas irreais criadas sobre o processo de ensino-aprendizagem desenvolvido pelos docentes.

Surgiu a questão do estereótipo e do preconceito em relação à profissão de SE, sobre o assunto as autoras Oliveira e Portela (2021) apontam a problemática, salientando uma transformação positiva nesse aspecto, mesmo que ainda de forma tímida. Em relação à expectativa da instituição, fica evidente que permeiam valores próprios da Educação Profissional e Tecnológica (EPT), assim como o propósito social do curso. Demarcam-se, também, as dificuldades desses docentes em atender à expectativa institucional, pois emergem as fragilidades ligadas às condições necessárias para o pleno desenvolvimento das atividades docentes (carga horária mínima das disciplinas, quantidade de laboratórios, materiais

\footnotetext{
${ }^{9}$ Representa a expectativa do Estado, da política pública. 
adequados etc.), além da ausência de diálogo horizontal entre o IFMT - Campus Cuiabá e os docentes, que serviria para alinhar a ações de implementação da política pública.

Além disso, duas de três externalidades apontadas por Lipsky (1969), que ameaçam a realidade do burocrata do nível de rua, podem ser identificadas nesse terceiro bloco, propriamente: recursos inadequados e expectativas sobre o desempenho do trabalho. A primeira atinge materialmente a prestação dos serviços públicos; por sua vez, a segunda se relaciona com o desempenho do trabalho desses profissionais que se desenvolve em resposta às expectativas ambíguas e contraditórias geradas pelos vários interesses conflitantes (LIPSKY, 1969).

O quarto bloco aborda a burocracia e os recursos disponíveis para a prática docente. A Docente 01 enxerga a burocracia como algo natural para uma instituição pública de educação e que a falta de recursos/estrutura impede o desenvolvimento ideal do processo de ensinoaprendizagem, especialmente: falta de laboratórios, diversificação dos espaços pedagógicos, laboratórios de informática que não conseguem atender a todas as demandas.

O Docente 03 aponta que muitas vezes os recursos não são o problema, mas sim “o cansaço e a falta de motivação dos alunos", o que afeta o processo de ensino-aprendizagem. Relata, ainda, impressões acerca da tendência de muitos discentes preferirem a abordagem tradicional (método conteudista) de interação em aula, pois quer "ser aprovado sem muitas dificuldades, sem muito trabalho, porque ele já chega ali exaurido, cansado de todas as outras responsabilidades e papéis que ele tem, é do trabalho, do estágio, da casa, da família, então ele só quer terminar aquilo". Importante demarcar que o curso de SE é noturno, composto em sua maioria por discentes que trabalham e/ou fazem estágio remunerado durante o dia.

No parágrafo acima constam os dados do quarto bloco de perguntas que continua explorando os recursos necessários para o pleno desenvolvimento do processo de ensinoaprendizagem. Os achados se alinham ao encontrado no bloco anterior, com um acréscimo trazido pelo Docente 03, que pontua a motivação dos discentes como componente relevante para o pleno atendimento da política pública de educação.

O quinto bloco foca nas ameaças à autoridade do docente existentes em sua prática. Todos afirmam que nunca perceberam sua autoridade ameaçada, que existe liberdade de atuação no IFMT. Os Docentes 01 e 02 apontam, ainda, que as regras e a hierarquia da citada instituição contribuem para um ambiente livre e autônomo de prática docente. Nesse caso, o bloco de perguntas buscou provocar o diálogo sobre uma possível externalidade que não foi tocada pelos entrevistados, inclusive, foi a única não apontada no terceiro bloco de perguntas, 
no caso seriam as ameaças e os desafios à autoridade. Sobre o tema, Lipsky (1969) explica que situações de ameaças de danos físicos e psicológicos podem ocorrer na esfera da atividade docente.

O sexto bloco indaga se o público do SE demanda do docente práticas diferentes ou adaptadas em relação a outros públicos/cursos/níveis de ensino. A Docente 01 pontua que depende da composição da turma do SE, pois, em alguns casos, discentes específicos precisam de uma atenção diferenciada.

A Docente 2 expressa que "sim, eu identifico", principalmente porque muitos discentes "chegam com uma expectativa" irreal, apesar disso, ao longo da interação, acabam compreendendo como será desenvolvida a disciplina. Outrossim, acrescenta que geralmente recebe um feedback positivo ao final do curso: “[...] eles gostam, eles entendem a metodologia”.

O Docente 3 aponta que a diferença na prática está ligada às condições gerais que o discente do nível superior chega para interagir nas aulas: "eles chegam na sala de aula cansados e às vezes pouco motivados, e aí eles acabam querendo apenas cumprir a tabela e não estão muito preocupados com a própria formação deles".

É perceptível pelos dados do parágrafo anterior como a interação docente e discente deve considerar a discricionariedade como componente invariável. A adaptação que o docente deve realizar para mediar o processo de ensino-aprendizagem acaba por repercutir na implementação da política pública e, logo, a autonomia/independência de atuação desse profissional impacta o cidadão (discente) e pode modificar a pretensão inicial constante na formulação da política pelo Estado (LIPSKY, 1980).

De forma mais objetiva, os docentes entrevistados identificam que existem diferenças na prática docente exercida no SE e em outros cursos. Apontam que a diferença identificada possui como causa primária as condições dos discentes matriculados no curso. Fazendo um paralelo com a teoria de referência (LIPSKY, 1969, 1980), a interação com o cidadão, no caso os discentes, é marcada por incertezas e pressões ${ }^{10}$ e tais características retroalimentam a manutenção da discricionariedade do docente.

A dinâmica em questão tem impacto na vida dos discentes, visto que a função exercida pelo servidor público (docente) define a forma de tratamento do 'cliente' (discente), calibrando

\footnotetext{
${ }^{10}$ Geradas por motivos diversos como ambiente, características próprias dos agentes envolvidos, estrutura institucional e outros.
} 
a relação institucional dos cidadãos com o Estado (LOTTA, 2010) e resultando em políticas públicas próprias a cada realidade (COSTA FILHO; GONÇALVES-COSTA; COSTA, 2018).

O sétimo bloco questiona se existe distância entre o planejamento da instituição e os interesses formativos dos discentes, bem como indaga como essa dinâmica afeta a prática docente. A Docente 01 interpreta que, de um lado, o discente desinteressado age mediante ações que geram benefícios como nota ou certificados; de outro, a instituição cobra que as práticas docentes coloquem os discentes como parte dos processos de ensino-aprendizagem e, por sua vez, o docente acaba por se esforçar para "dar o melhor para eles (estudantes)".

A docente ainda afirma que gosta de inovar ao implementar dinâmicas para reforçar o aprendizado. A docente 02 reconhece as várias expectativas existentes "dentro da administração há uma [...], dentro da coordenação há outra, para os discentes há outra" e lida com tudo isso realizando um bom trabalho naquilo que se predispôs a fazer, e complementa:

[...] ser professor, ser docente, no Brasil, são variáveis que não nos permite dizer que é uma função tranquila, não é uma profissão tranquila, mas é algo que é muito gratificante, e quem gosta realmente se identifica e tenta fazer o melhor possível, e eu estou dentro dessa margem aí, desse pessoal que gosta de ser professor. (Docente 02, entrevista semiestruturada)

O Docente 03 defende que os interesses da instituição (prática, planejamento e objetivos do curso) "não são muito claros, porque não existe uma discussão, sobre isso, coletiva". Ademais, pontua que os docentes não têm muito interesse em entender outras necessidades (interdisciplinaridade, multidisciplinaridade etc.) para além do básico (cumprir o horário, ministrar aula etc.), o que resulta numa construção hegemonicamente individual em que "o professor se debruça sobre a sua própria disciplina e meio que cria uma miopia”.

Provocou-se a reflexão acerca do trabalho do docente considerando o distanciamento entre os interesses/expectativas dos discentes e da instituição no sétimo bloco de perguntas. Os entrevistados nesse e nos demais blocos (principalmente o terceiro bloco de perguntas) demarcam essa distância caracterizando, de um lado, discentes desinteressados e, de outro, a instituição que tem definido normativamente seu escopo, mas não consegue realizar esforços dialógicos e integradores para transpor para a prática esse conteúdo normativo, prejudicando a implementação adequada da política pública educacional.

Invariavelmente a formulação da política pública está em desajuste com a sua implementação, que pode ser ocasionada por diversos fatores, dentre eles, políticas com 
característica top-down ${ }^{11}$ (PRESSMAN; WILDAVSKY, 1984), assimetrias de informação, diretrizes ambíguas devido a disputas políticas (EXNER et al., 2021), incapacidade técnica da burocracia de médio escalão ${ }^{12}$ e de nível de rua.

O contexto descrito acima é revelador, a falta de interseção, sintonia, ajuste entre o que deseja o discente, o que planeja a gestão e o que executa o docente acaba refletindo na dificuldade em constituir de forma eficiente a educação pública integral, de qualidade e politécnica desejada pela sociedade. Percebe-se, no tema, persistente e evidente fragilidade na formulação da política pública de educação que é escancarada na implementação quando o planejamento se distancia da realidade vivenciada na ponta do serviço público. Logo, esse descompasso potencializa o campo de discricionariedade e independência do docente que acaba por fazer a política pública (LIPSKY, 1980).

O oitavo bloco debate a liberdade/discricionariedade do docente no processo de ensino aprendizagem e como essa prática afeta a política pública de educação. A Docente 01 narra sua inexperiência inicial na docência, o que acabou por criar certa dificuldade no exercício da liberdade acadêmica, que não afetou sua prática docente, pautada na aproximação entre a teoria e prática.

A Docente 02 afirma possuir liberdade que são fundados nos direcionamentos contidos na ementa da disciplina e no PPC do curso, detalha ainda: "tenho liberdade para poder, no meu planejamento, explorar aquilo que eu acho mais conveniente, acho que aquilo que vai favorecer o desenvolvimento laboral no meu discente, lá no mercado de trabalho". Ademais, fundamenta a sua docência na aproximação entre a teoria e a prática para que o discente tenha sucesso na vida profissional.

O Docente 03 percebe liberdade na prática profissional, pois “cada professor pode usar o método que melhor lhe convém, que ele acredita, apesar de que às vezes isso pode distanciar um pouco do planejamento, que é um planejamento comum"; quanto à constituição da política pública da educação, o entrevistado defende que quando o docente provoca uma mediação crítica o processo tende a afetar positivamente a política ao contribuir para a formação integral do cidadão, com indivíduos mais emancipados e livres.

Confirmando as impressões fixadas nos blocos anteriores e na teoria de referência (LIPSKY, 1969; 1980), os entrevistados afirmam possuir total liberdade para a sua prática

\footnotetext{
${ }^{11}$ A política pública é formulada por decisores que ocupam os espaços institucionais de poder, persiste a centralidade das decisões do governo central.

${ }^{12}$ Conforme definição dessa agenda de pesquisa (JORGE, 2012; LOTTA; PIRES; OLIVEIRA, 2014).
} 
docente. Elucida notar a consciência existente nos docentes estudados de que a sua liberdade profissional está intimamente ligada aos limites impostos pela instituição ${ }^{13}$ e pela interação e interesse dos agentes envolvidos na política pública educacional (docente, discente e instituição). A liberdade/discricionariedade dos docentes cria incentivos para esses modelarem a política pública em que estão inseridos, o que implica profundamente na vida dos cidadãos que utilizam desse serviço público, no caso os discentes.

De todo exposto, é possível observar algumas evidências empíricas que confirmam questões teóricas propostas por Lipsky $(1969 ; 1980)$. Conforme os dados e as reflexões desta pesquisa, o docente do curso de SE tem consciência que está inserido em uma estrutura burocrática institucional que pauta a sua atuação profissional e que dinamiza com sua discricionariedade (liberdade).

Persistem expectativas e interesses diversos nesse recorte específico que trata do lugar de encontro do governo com o cidadão. No caso analisado do curso de SE, de um lado, observase os discentes nem sempre motivados; de outro, uma instituição incapaz de articular a desejada integralidade educacional que convirja os vários esforços em torno de um esforço pedagógico interdisciplinar ou transdisciplinar; e, no meio disso tudo, está o docente que acaba por vezes enfrentando um ambiente com recursos inadequados, expectativas ambíguas dos demais agentes (discentes e instituição) e concentrando sua prática em pressupostos próprios nem sempre conectados com um esforço pedagógico interdisciplinar ou transdisciplinar que deveria existir.

A questão da discricionariedade do docente é mencionada com muita saliência. É um componente invariável no processo educacional que repercute na implementação da política pública e impacta na vida do discente. Os dados apontam que a discricionariedade na prática docente do SE está ligada às condições em que o discente do curso possui, de como ele chega ao curso. Logo, é o componente que calibra substantivos recursos na relação entre o cidadão e o Estado, pois, para a teoria adotada, a atividade do docente representa de forma essencial o tratamento que o cliente recebe do Estado; assim, o resultado da política pública difere a depender da realidade.

O último aspecto que merece destaque é o fato da formulação da política pública educacional estar em desajuste com a sua implementação, em especial os dados apontam que persiste uma falta de sintonia no curso de SE entre o que deseja o discente, o que planeja a

\footnotetext{
${ }^{13}$ Entendida aqui tanto como abstração jurídica quanto como conjunto normativo.
} 
gestão e o que executa o docente. Nessa falta de sintonia entre os principais agentes do processo educacional, cabe ao docente garantir e mediar a política pública, pautado na prática de sua discricionaridade e autonomia.

Um ponto de equilíbrio mais convergente entre agentes, interesses e ações no curso de SE poderia contribuir para a consolidação de resultados mais positivos na política educacional, gerando maior bem-estar no ambiente escolar. A pesquisa de Puentes-Montoya (2018) traz exemplo de que é possível buscar a implementação de ações na área de Educação harmonizando autonomia docente e gestão governamental, sem deixar de cuidar dos indivíduos imbuídos nessa relação.

Identificou-se, ainda, que as trajetórias dos docentes entrevistados possuem uma semelhança bem saliente: todos os entrevistados foram discentes do IFMT e acessam a mesma instituição na condição de docentes ainda muito jovens, no início da vida profissional.

\section{CONSIDERAÇÕES FINAIS}

A educação pública, gratuita e de qualidade é um direito social do cidadão e sua consolidação se revela como caminho necessário para constituir equidade em um país marcado pela desigualdade de toda monta. A RFEPCT é parte do ambiente da educação pública no Brasil, integra essa rede, os Institutos Federais.

Nesse contexto, a presente pesquisa tratou do IFMT, propriamente do curso de SE oferecido nesta instituição. Assim, a pesquisa analisa a percepção dos docentes do curso de bacharelado SE, do IFMT - Campus Cuiabá Octayde Jorge da Silva, em relação a sua atuação na política pública de educação enquanto burocratas de nível de rua.

Foi possível depreender, pelos dados coletados e reflexões realizadas, algumas evidências empíricas que confirmam reflexões teóricas propostas por Lipsky $(1969 ; 1980)$, conforme segue: 1) o docente do curso de SE está inserido em uma estrutura burocrática institucional que pauta a atuação profissional e que afeta a sua discricionariedade (liberdade); 2) as expectativas e interesses diversos foram identificadas; de um lado, discentes desmotivados e, de outro, a instituição incapaz de articular um esforço pedagógico na integralidade desejada pela política educacional; e, no meio, o docente que enfrenta um ambiente com recursos inadequados, expectativas ambíguas e concentrando a sua prática em pressupostos próprios que não recebe incentivos institucionais para convergir em um esforço pedagógico interdisciplinar ou transdisciplinar no curso; 3) a discricionariedade do docente do SE repercute na implementação da política pública e relaciona-se com as condições que o discente do curso 
possui; 4) o docente do curso de SE relata que não sofre ameaças da gestão superior e possui liberdade para desenvolver suas atividades; 5) a persistência de um desajuste entre a formulação da política pública educacional e a sua implementação, caracterizada pela falta de sintonia entre o que deseja o discente, o que planeja a gestão e o que executa o docente.

Lembrando que toda pesquisa é um recorte específico da realidade e é positivo apresentar eventuais fragilidades identificadas no presente estudo. Primeiro, como é uma pesquisa exploratória, não existem marcos bem estabelecidos na perspectiva adotada, logo, este esforço inicial pode apresentar algumas lacunas. Segundo, o número pequeno da amostra, à primeira vista, pode causar dúvida quanto ao potencial empírico e analítico dos dados, contudo, a pesquisa demonstra que foi suficiente para trazer uma complexidade de achados, visto que as entrevistas geraram uma grande quantidade de dados relevantes. Terceiro, a adaptação da perspectiva teórica adotada, que comumente é utilizada para analisar política pública, tem seus desafios que necessitam ser superados e isto foi o pretendido pelo estudo.

A agenda futura aponta principalmente para pesquisas que tratam: das percepções de agentes da instituição e dos discentes acerca desse burocrata de nível de rua que executa as políticas públicas de educação; de um maior entendimento sobre a discricionariedade existente na atuação docente da rede pública e como ela impacta na vida dos estudantes; as condições adversas que o docente enfrenta na execução do seu serviço público; entre outros.

Aponta-se a relevância social da pesquisa. A abordagem prioriza esse momento que o serviço público encontra a sociedade; no presente estudo, isso se dá na atividade docente, na interação instituição, docente e estudante. Assim, compreender como pressões, ambiente, dilemas, interesses, agentes, expectativas dinamizam nessa arena é essencial para revelar pontos positivos e negativos que ocorrem na implementação da política pública com afetação na fase anterior (formulação) e posterior (avaliação) deste ciclo. De forma mais prática, a análise do curso de SE possibilita que os interessados traduzam melhor o fenômeno que estão inseridos, contribuindo para diminuir eventuais assimetrias de informações e otimizando as decisões de todos os envolvidos.

Por fim, a agenda de pesquisa da área de educação e de ensino é produtiva, vários desenhos de pesquisa contribuem com o debate. Este artigo buscou inovar ao trazer um estudo estruturado por uma perspectiva teórica não usual na educação e ensino, que privilegia o diálogo acerca do momento em que a política pública de educação encontra o cidadão. 


\section{REFERÊNCIAS}

BARRETO, Maiara Couto; COSTA, Thiago de Melo Teixeira da; MEDIOTTE, Elias José. A discricionaridade dos burocratas de nível de rua no contexto da implementação de políticas públicas: uma revisão sistemática. In: Encontro Nacional de Ensino e Pesquisa do Campo de Públicas, 2020, Rio Grande do Norte. Anais de evento. Rio Grande do Norte: ANEPCP, 2020. p. $1688-1700$.

BRASIL. Ministério da Educação. Institui as Diretrizes Curriculares Nacionais para o curso de graduação em Secretariado Executivo e dá outras providências. Resolução nº 3 , de 23 de junho de 2005.

BRASIL. Lei n ${ }^{\circ}$ 7.377, de 30 de setembro de 1985. Dispõe sobre o Exercício da Profissão de Secretário, e dá outras providências. Brasília, DF. Disponível em: http://www.planalto.gov.br/ccivil_03/leis/17377.htm\#: :text=LEI\%20No\%207.377\%2C\%20D E,eu\%20sanciono\%20a\%20seguinte\%20Lei\%3A\&text=1\%C2\%BA\%20\%2D\%20O\%20exer c\%C3\%ADcio\%20da\%20profiss\%C3\%A3o,\%C3\%A9\%20regulado\%20pela\%20presente\%2 OLei. Acesso em: 15 mai. 2021.

BRASIL. Lei $n^{\circ}$ 9261, de 10 de janeiro de 1996. Altera a redação dos incisos I e II do art. $2^{\circ}$, o caput do art. $3^{\circ}$, o inciso VI do art. $4^{\circ}$ e o parágrafo único do art. $6^{\circ}$ da Lei $n^{\circ} 7.377$, de 30 de setembro de 1985. Brasília, DF. Disponível em:

http://www.planalto.gov.br/ccivil_03/leis/L9261.htm\#art1. Acesso em: 15 mai. 2021

CANDAU, Vera. Maria. Multiculturalismo e educação: desafios para a prática pedagógica. In: CANDAU, Vera. Maria. (Org.) Multiculturalismo: diferenças culturais e práticas pedagógicas. Petrópolis: Vozes, p. 13-37, 2008.

CERTEAU, Michel. A invenção do cotidiano: artes de fazer. Petrópolis: Vozes, 1994.

COSTA FILHO, José Vinicius; COSTA, José Vinicius; GONÇALVES-COSTA, Lyssa. A prática docente e a evasão dos cursos PROEJA no IFMT - Campus Cuiabá: uma perspectiva dos burocratas de nível de rua. Revista Prática Docente, v. 2, n. 1, p. 82-96, 2017.

COSTA FILHO, José Vinicius; GONÇALVES-COSTA, Lyssa; COSTA, José Vinicius. Prática docente e burocracia de nível de rua: uma proposta de análise teórica. Revista Prática Docente, v. 3, n. 1, p. 316-333, 2018.

EXNER, Marina Katurchi; CORRÊA, Marcela Garcia; LOTTA, Gabriela; FARAH Marta Ferreira Santos. Implementando diretrizes de gênero na escola: entre a obediência legal e cultural. Revista @mbienteeducação, [S.1.], v. 14, n. 1, p. 33-56, jan. 2021. ISSN 19828632 .

FRANCO, Maria Amélia Santoro. Pedagogia como ciência da educação. São Paulo, Cortez. 2008.

FREIRE, Paulo. Pedagogia da Autonomia: saberes necessários à prática educativa. 59a ed. Rio de Janeiro / São Paulo: Paz \& Terra, 2019. 
GADOTTI, Moacir. Pedagogia da Práxis. $4^{a}$ ed. São Paulo. Cortez. Instituto Paulo Freire, 2004.

HOOKS, Bell. Ensinando a transgredir: a educação como prática de liberdade. 2. ed. São Paulo: Martins Fontes, 2017.

JORGE, Ilza Valéria M. A importância da burocracia do "nível de rua" em processos de mudança organizacional: o caso do hospital municipal infantil menino Jesus. Dissertação (Mestrado em Gestão e Políticas Públicas) - Escola de Administração de Empresas de São Paulo da Fundação Getúlio Vargas, 2012.

LAKATOS, Eva Maria; MARCONI, Marina de Andrade. Metodologia do trabalho científico. 5. Ed. São Paulo: Atlas. 2001.

LOTTA, Gabriela Spanghero. Implementação de Políticas Públicas: o impacto dos fatores relacionais e organizacionais sobre a atuação dos burocratas de nível de rua no Programa Saúde da Família. 295f. Tese (Doutorado em Ciências políticas) Departamento de Ciências Políticas, Universidade de São Paulo, 2010.

LOTTA, Gabriela Spanghero; PIRES, Roberto Rocha C.; OLIVEIRA, Vanessa Elias. Burocratas de médio escalão: novos olhares sobre velhos atores da produção de políticas públicas. Revista do Serviço Público - RSP, v. 65, n. 4, p. 463 - 492, 2014.

LIPSKY, Michael. Toward a Theory of Street-level Bureaucracy. In: HAWLEY, Willis; LIPSKY, Michael (ed.). Theoretical Perspectives on Urban Politics. Eaglewood Cliffs, NJ: Prantice Hall, 1969.

LIPSKY, Michael. Street-level bureaucracy: dilemmas of the individual in public services. New York: Russell Sage Foundation, 1980.

MINAYO, Maria Cecília de Souza. O desafio do conhecimento. Pesquisa qualitativa em saúde. São Paulo: Hucitec-Abrasco. 1992.

OLIVEIRA, Tatiane. PORTELA, Keyla. Empregabilidade profissional: um estudo sobre os egressos do curso de Bacharelado em Secretariado Executivo do Instituto Federal de Mato Grosso - IFMT. Revista SCRIBES, Viçosa/MG, v. 2, nº 1, jan./jun., 2021. DOI: 10.33228/scribes.2021.v2.12189. Disponível em: https://periodicos.ufv.br/SCRIBES/article/view/12189/6880 . Acesso em: 04 out. de 2021, p. 23-51.

PORTELA, Keyla Christina Almeida; SCHUMACHER, Alexandre José; BORTH, Marcelo Rafael. Ferramentas do Secretário Executivo. 2.ed. Cuiabá/MT: Dos Autores, 2013.

PRESSMAN, Jeffrey L.; WILDAVSKY, Aaron. Implementation: how great expectations in Washington are dashed in Oakland. 3. ed. Berkeley: University of California Press, 1984.

PRODANOV, Cleber Cristiano; FREITAS, Ernani Cesar de. Metodologia do Trabalho Científico: Métodos e Técnicas da Pesquisa e do Trabalho Acadêmico, $2^{\mathrm{a}}$ Ed., Novo Hamburgo - RS, Associação Pró-Ensino Superior em Novo Hamburgo - ASPEUR Universidade Feevale, 2013. Disponível em: 
https://www.feevale.br/Comum/midias/0163c988-1f5d-496f-b118-a6e009a7a2f9/Ebook\%20Metodologia\%20do\%20Trabalho\%20Cientifico.pdf. Acesso em: 02/09/2021.

PUENTES-MONTOYA, Natália. Análise da discricionariedade dos professores como burocratas de nível de rua da política pública de educação. Dissertação. Fundação Getúlio Vargas. Escola de Administração de Empresas de São Paulo. São Paulo, 2018.

SILVA, Eliane Costa. Burocratas de nível de rua e a implementação do PROEJA: uma perspectiva de baixo pra cima. Dissertação (mestrado profissional em políticas públicas). Universidade Federal de Pernambuco, CFCH. Programa de Pós-Graduação em Ciência Política, Recife, 2016.

TARDIF, Maurice. Saberes docentes e formação profissional. Petrópolis, RJ: Vozes, 2002.

VEIGA, Ilma. Passos Alencastro. Inovações e projeto político-pedagógico: uma relação regulatória. Cad. Cedes, Campinas, v. 23, n. 61, p. 267-281, dezembro 2003. 